\title{
Nietzsche ou a eternidade do tempo*
}

\author{
Diego Sánchez Meca**
}

\begin{abstract}
Resumo: Este artigo propõe uma interpretação do Eterno Retorno a partir da função que ele exerce em relação aos objetivos do pensamento de Nietzsche. Ou seja, busca-se seu sentido no contexto do projeto do filósofo de transformação da cultura européia. Não se formula, pois, uma teoria nietzschiana sobre a essência verdadeira do tempo que se confrontaria com a concepção metafísica do tempo linear. Portanto, o Eterno Retorno não pretende ser um enunciado dirigido ao entendimento, mas sim, ser a expressão de um desafio e tarefa para a vontade. Assim, ainda que a doutrina do Retorno possua a forma de uma representação teórica, o decisivo não é sua validade ou verdade enquanto teoria, mas sim, seu valor enquanto fórmula da mais alta afirmação da vida e como instrumento necessário de seleção.
\end{abstract}

Palavras-chave: Eterno retorno - desafio - tarefa - afirmação - seleção

O tema do Eterno Retorno aparece tratado na obra de Nietzsche em dois tipos de textos bem diferentes entre si: por um lado, os científicos; por outro, os alegóricos. Os científicos são um conjunto de anotações feitas por Nietzsche, sobretudo entre 1881 e 1883, quando lê vários livros relacionados a um dos debates suscitados pelo descobrimento dos dois princípios da termodinâmica ${ }^{1}$. Mais precisamente, o debate era o da dissipação da energia ou morte térmica do universo, e nele polemizavam não só muitos cientistas (Vogt, Helmholtz, Blanqui, Clausius, Caspari, Thomson, Zöllner,

* Tradução de Vinicius de Andrade.

** Professor da Universidade de Madrid (UNED), Madri, Espanha. E-mail: dsanchez@fsof.uned.es.

1 Cf. principalmente Fragmentos póstumos. Madrid: Tecnos, 2010. vol III, pp. 441-453; KSA 10.643-667.

Cad. Nietzsche, São Paulo, n. 33, p. 181-196, 2013. I 181 
Meca, D. S.

Boltzmann e outros) como também alguns filósofos como Dühring, Edward von Hartmann, Engels, Wundt e outros. No debate, estavam, por um lado, os que sustentavam que o universo tivera um começo no tempo e que teria também um final. Quanto a esse final, os cientistas o postulavam na forma física de uma perda total de calor (ou seja, a morte térmica), enquanto que os filósofos o postulavam, no marco do idealismo, na forma metafísica de um estado de término ou consumação última do vir-a-ser do mundo. Por outro lado, em revanche, estavam os que acreditavam ser possível pensar em sucessivas condensações de energia por meio de determinados avatares cósmicos capazes de inverter a tendência entrópica à dissipação, os quais se apoiavam, sobretudo, no segundo princípio da termodinâmica. De modo que o universo nunca teria tido um início nem teria nunca um final. E o principal argumento para sustentar essa tese era que, na infinidade do tempo transcorrido, se um estado final do mundo fosse possível, ele teria de obviamente já ter sido alcançado, pois, caso contrário, o tempo não seria infinito $^{2}$. Isso significa que o segundo princípio da termodinâmica incide numa transformação dos conceitos de espaço, tempo e matéria que torna possível pensar, segundo esses cientistas, um universo enquanto eterna sucessão de formas novas.

No verão de 1881, Nietzsche lê a obra de Otto Caspari, Der Zusammenhang der Dinge, e se impressiona tanto com ela que decide continuar lendo todos os estudos citados ou debatidos nesse livro, meditando reiteradamente sobre os argumentos científicos a favor da hipótese da eternidade do mundo. De qualquer modo, quando se

2 Como se sabe, o primeiro princípio da termodinâmica é a lei da conservação de energia. Segundo ela, a energia não pode criar-se nem destruir-se, de maneira que a quantidade de energia transferida a um sistema em forma de calor mais a quantidade de energia transferida em forma de trabalho sobre o sistema deve ser igual ao aumento de energia do sistema. $\mathrm{O}$ segundo princípio é a lei da entropia. Segundo ela, a quantidade de entropia de qualquer sistema termodinamicamente isolado tende a aumentar com o tempo, de modo que quando uma parte de um sistema fechado interage com outra parte, a energia tende a dividir-se por igual até que o sistema alcance um equilíbrio térmico.

182 I Cad. Nietzsche, São Paulo, n. 33, p. 181-196, 2013. 
lêem bem essas anotações de Nietzsche, o que se vê nelas são, além de muitas citações literais do que o filósofo está lendo, simples comentários guiados mais pela curiosidade despertada pelo debate do que pela intenção ou propósito de buscar neles elementos com os quais ele poderia elaborar uma nova teoria sobre o tempo. Por fim, nesses textos que chamamos científicos, não encontramos nada que possa parecer uma formulação teórica - nem sequer um esboçoivro, meditando reiteradamente sobre os argumentos cient os estudos citados ou debatidos nesse livro, meditando reiteradamente - do eterno retorno enquanto proposta argumentativa com a qual Nietzsche quereria confrontar-se com a concepção linear do tempo própria à metafísica clássica ${ }^{3}$.

É preciso dirigir o olhar, pois, aos textos alegóricos sobre o eterno retorno que se encontram basicamente no Zaratustra, a fim de investigar se neles encontramos algo mais substancial que nos anteriores. Sabe-se que, além desses fragmentos póstumos "científicos" aos quais acabei de me referir e dos textos alegóricos que encontramos no Zaratustra aos quais me referirei agora, Nietzsche não fala em nenhum outro lugar da sua obra publicada sobre o eterno retorno, salvo em duas outras ocasiões, a saber, o parágrafo 341 de A gaia ciência e o famoso aforismo 56 de Para além de bem e mal que se encerra com a expressão circulus vitiosus deus, sem que se diga, na verdade, grande coisa em nenhum dos dois. Tendo em vista esse escamotear mais ou menos premeditado, é necessário considerar um desenvolvimento e uma formulação argumentativa do eterno retorno como possuindo um significado importante. A esse respeito, a pergunta é: por que Nietzsche designa e assinala, várias vezes ao longo de sua obra, a doutrina do eterno retorno como

3 Para uma exposição mais detalhada sobre esse debate, em conexão com o pensamento de Nietzsche, cf. D'Iorio, P. La linea e il circolo. Cosmologia e filosofia dell'eterno ritorno in Nietzsche. Genova: Pantograf, 1995. Cf. também, acerca da posição nietzschiana, BRUSOTTI, M. Die Leidenschaft der Erkenntnis. Philosophie und Lebenstaltung bei Nietzsche von Morgenröthe bis Also sprach Zarathustra. Berlim: de Gruyter, 1997. 
Meca, D. S.

seu pensamento mais profundo e abismal, como pedra fundamental de todo seu arcabouço teórico e crítico, e, no entanto, quando trata dela em seus textos, o faz com a ambiguidade de meros símbolos poéticos e alegorias tais como encontrados nos cantos de Zaratustra? Esses símbolos e alegorias referem-se à doutrina do eterno retorno de maneira puramente alusiva e elusiva, como se manifestamente carecessem de uma formulação posterior mais completa e precisa que, contudo, nunca chegou a ser produzida. Aliás, há várias passagens no Zaratustra em que se insiste na necessidade de assumir e afirmar o pensamento do eterno retorno sem que esse pensamento tenha sido antes exposto explicitamente. Ele também não o será em momento posterior algum.

Portanto, e à luz disso, é preciso concluir necessariamente uma coisa: Nietzsche não pensa a idéia do eterno retorno como uma nova teoria sobre o tempo alternativa à concepção metafísica vigente. Na verdade, é preciso atentar para o fato de que ele nunca se refere ao eterno retorno como uma "teoria", falando sempre numa "profecia", num "anúncio" ou numa "doutrina". Por isso, o filósofo não vê a necessidade de desenvolver argumentativamente o pensamento. No fim das contas, apresenta-o não como uma fórmula ou um enunciado dirigido ao entendimento e à compreensão, mas como a expressão de um desafio, um esconjuro (conjuro), uma tarefa dirigida à vontade. $\mathrm{O}$ eterno retorno tem de ser, pois, o objetivo de uma "experiência", ou melhor, de uma decisão da vontade enquanto fundamento da prova mesma na qual consiste todo o experimento nietzschiano de transvaloração de todos os valores e de superação do niilismo.

$E$ isso que se deduz claramente da alegoria narrada no canto intitulado "Da visão e enigma", na terceira parte do Zaratustra (Za/ ZA, Da visão e enigma; KSA 4.197-202). Nessa passagem, a visão de Zaratustra fala sobre um jovem pastor que, ao chão, se retorce de dor, pois uma enorme serpente negra havia se introduzido em sua garganta e o estava asfixiando lentamente. A serpente negra simboliza aqui o niilismo. Zaratustra tenta, inutilmente, arrancar 
a serpente da garganta do pastor puxando-a. Porque o niilismo, quase já completamente introduzido no homem, incorporado a ele, não pode ser vencido a não ser por aquele que dele padece. De modo que a serpente só poderia ser morta se o pastor lhe mordesse a cabeça. E, com efeito, apenas quando o pastor faz aquilo que Zaratustra lhe recomenda aos gritos, ou seja, a morde e a cospe, é que ele se vê livre da serpente e com a vida salva ${ }^{4}$ O relato dessa visão encerra-se com uma indicação muito importante: quando o pastor se levanta após ter mordido a cabeça da serpente, o texto diz: "Não mais pastor, não mais homem - um transfigurado, um iluminado, que ria! Nunca ainda sobre a terra riu um homem, como ele ria!" (Za/ZA, Da visão e enigma, 2, KSA 4.202) $)^{5}$. Era o Übermensch. Essa alegoria ensina, pois, que a superação do niilismo depende de uma decisão suprema da vontade pela qual liberamos nossa existência do niilismo e damos o primeiro passo em direção a um über, a um além do homem (Mensch) como modo novo de ser e existir. E qual é essa decisão? Como veremos em seguida, é a decisão de afirmar, de dizer sim ao eterno retorno do mesmo com tudo aquilo que ele implica e significa.

No entanto, antes de abordar a explicação, parece-me conveniente destacar essa última coisa, qual seja: precisamente por essa condição de último recurso, de pedra fundamental, que o eterno retorno possui para o projeto que Nietzsche elabora de transformação da cultura européia para impeli-la para além do niilismo. O decisivo não é a validade do eterno retorno nem sua coerência ou verdade a partir do ponto de vista teórico, mas seu valor como

4 Conforme o comentário de Heidegger sobre esse canto em: HEIDEGGER, M. Nietzsche. Trad. J. L. Vermal. Barcelona: Destino, 2000. vol. 1, pp. 237ss, 320ss, 345ss, 353ss. Cf. também: SÁNCHEZ MECA, D. Nietzsche: la experiência dionisíaca del mundo. Madrid: Tecnos, 2009 (4 ed.). pp. 359ss.

5 Salvo indicação contrária, as traduções das passagens de Nietzsche são de minha autoria. Na presente citação, utilizei a tradução de Rubens Rodrigues Torres Filho que consta no volume sobre Nietzsche da Coleção "Os pensadores" (N. do T.). 
esconjuro - diz Nietzsche - como esconjuro da mais alta afirmação da vida que se possa imaginar ${ }^{6}$.

Uma vez delineado o contexto segundo o qual o pensamento do eterno retorno não seria nem uma teoria nem uma proposta argumentada de uma tese determinada sobre o ser do tempo, podemos compreender melhor as alusões que ocasionalmente Nietzsche faz sobre essa doutrina, quando diz, creio que de maneira mais irônica que séria, que ela deve ser entendida, na verdade, como uma nova religião ${ }^{7}$. O filósofo chama a atenção para o fato de que muitas das representações da religião cristã não têm nenhum fundamento de verdade racional, e isso não as impediu de terem sido muito eficientemente incorporadas como condição de vida por todos os cristãos de todos os tempos ou de terem determinado durante séculos a configuração de nossos dispositivos pulsionais. Por exemplo, a representação puramente imaginária do inferno, da condenação eterna ardendo em inextinguíveis chamas incandescentes e na qual se é atormentado sem descanso por legiões de demônios que pululam com seus tridentes e chifres, não precisou nunca de fundamento científico que demonstrasse sua verdade e, no entanto, produziu sem dúvida alguma um enorme efeito sobre a conduta dos indivíduos durante dois mil anos. Para que penetrasse profundamente, precisou de muito tempo e da coação tirânica de um poder autoritário tal como o da Igreja. Pois o mesmo - diz Nietzsche -, ou pelo menos algo parecido, teria que acontecer com o eterno retorno: não é preciso que ele seja demonstrado como a verdadeira realidade do tempo. Nem sequer precisa ser uma idéia verossímil ou provável, o que ela precisa é ser uma idéia eficaz enquanto instrumento de transformação e educação, uma idéia assumida, pois simplesmente se quer afirmá-la como tal e dizer sim a ela.

Uma vez explicado o estatuto que me parece ter essa idéia para o ponto de vista de Nietzsche, vamos passar a examiná-la em

6 Nachlass/FP 1888, (9) 24 [1], KSA 13.626-629.

7 Cf. Nachlass/FP 1881, 11 [158], KSA 9. 503.

186 I Cad. Nietzsche, São Paulo, n. 33, p. 181-196, 2013. 
seu sentido profundo, nessa eficácia transformadora ou transfiguradora que o filósofo lhe confere. Pois é nesse dirigir-se à vontade e à decisão que o eterno retorno encontra seu sentido próprio. Para investigar esse sentido, e também para seguir alguma pista, deixar-nos-emos guiar pela indicação feita várias vezes por Nietzsche: o eterno retorno é a fórmula da mais alta afirmação da vida que se possa imaginar e, enquanto tal, é o instrumento necessário para discriminar entre os homens niilistas e o além-do-homem. Todos sabem que a concepção linear do tempo acabou por se impor historicamente no Ocidente como consequência do triunfo do cristianismo, que suplantou e substituiu a concepção circular própria ao paganismo antigo. Na verdade, essa nova concepção linear não era senão a consequência mais direta da nova compreensão cristã do acontecer do mundo enquanto criação, pecado original, redenção e escatologia. De maneira que, segundo essa nova concepção, o mundo tem um começo no passado, que é a criação, e terá um final no futuro com a parusia, quando o Redentor voltará triunfante em sua condição de juiz supremo universal. Portanto, disso resulta uma estrutura temporal composta de maneira linear, com passado, presente e futuro.

Contudo, se prestarmos um pouco mais de atenção, o que na verdade compõe essa estrutura linear é um encadeamento de momentos pontuais sobre os quais não se pode afirmar que tenham, a rigor, consistência ou existência alguma. Porque cada instante presente dessa cadeia, para ser e existir, tem de suprimir o instante anterior, tem de matar, por assim dizer, o pai que acaba de engendrá-lo, para que ele mesmo seja morto imediatamente pelo instante seguinte, seu filho para o qual acaba de dar a vida. E esse filho, ou seja, o instante seguinte, por sua vez será suprimido e suplantado imediatamente pelo instante seguinte e assim sucessivamente. Ou seja, o tempo linear é uma cadeia de instantes que se suprimem, que se anulam e se aniquilam incessantemente uns aos outros. Trata-se de uma sucessão edípica na qual todos os instantes ou momentos são mortos, tendo apenas existido sem que nenhum deles 
Meca, D. S.

chegasse a conter a vida ou pudesse alcançar uma plenitude de existência, de valor e significado por si mesmo. Posto que a existência e o significado de cada instante dependem de sua conexão com o passado, que já não existe, e de sua antecipação do futuro, que todavia não chegou a ser, nenhum dos momentos do tempo linear em sua particularidade de presente, passado ou futuro chegam a ser momentos vivos, depositários de uma plenitude autônoma de significado e existência. A causa dessa estrutura edípico-escatológica da temporalidade, a vida, o sentido e o valor se encontram sempre situados ou mais aquém ou mais além de um presente que nunca se realiza.

Assim, não é difícil dar-se conta de que essa é a forma mais extrema e radical que se pode pensar de uma negação à vida, pois implica não só uma desvalorização moral, geral e global dela, mas também por representar sua negação instante por instante, despojando-a de realidade e valor ao introduzir a não-existência, o nada como conteúdo próprio a cada um dos instantes que a constituem. Donde a convicção do niilista que vive segundo essa experiência da temporalidade linear de que a vida não é, na verdade, um viver, mas somente um vão e ilusório passar; uma pura aparência de sonho cujo pano de fundo feito de nada a revela como sendo sem sentido, como absurda em si mesma, sendo necessário projetar o sentido e o valor num outro mundo, numa transcendência. Nietzsche pode afirmar, pois, com toda lógica, que a concepção linear do tempo é a manifestação principal do ressentimento e do espírito de vingança contra a vida, de modo que somente nos veríamos livres do niilismo se acessássemos outro modo de entender e viver a temporalidade que fosse, por sua vez, sua redenção. Nesse contexto, o eterno retorno se propõe, então, a ser justamente esse outro modo de viver o tempo, oferecendo-se como desafio à vontade cuja afirmação a faria acessar outra forma muito diferente de viver a temporalidade. $\mathrm{Ou}$, mais concretamente, o eterno retorno se oferece como a decisão para um novo modo de aplicar a si mesmo a exigência ética de articular o tempo de modo que dessa exigência se siga o gozo e a afirmação da vida em vez de sua negação extrema. 
Em que consistiria, pois, essa outra forma de viver o tempo que acessaríamos com a afirmação do eterno retorno, e o que implica e representa esse dizer sim? Nietzsche sugere uma explicação na mesma alegoria do canto antes citado "Da visão e enigma". A visão é a que narramos antes. Agora abordaremos o enigma, que não é outro senão "o lugar" de onde Zaratustra fala e grita ao pastor, incitando-o a morder a cabeça da serpente. Que "lugar" é esse? Segundo o texto, Zaratustra vê a si mesmo sob o portal do instante (Augenblick), onde se cruzam os caminhos dos tempos, o passado e o futuro ${ }^{8,9}$. Isso quer dizer que Zaratustra se situa no instante presente. Situar-se no presente, viver nele, é isso o que significa e implica a afirmação do eterno retorno. E isso não é algo ao qual se pode chegar facilmente ou onde se pode permanecer sem esforço ou passivamente. Isso requer, como sugere o enigma, reunir no instante presente caminhos ou avenidas dos tempos, do passado e do futuro. Portanto, é preciso ser capaz de reordenar a sucessão edípica e vertiginosa dos momentos do nosso tempo linear (passado, presente e futuro), submetendo sua pluralidade a uma unidade para que se lhes confira, assim, um sentido novo.

Como isso é feito? Impondo uma forma a essa unidade do instante presente, ou seja, uma interpretação que reinterprete o passado que nos conduziu até aqui e reoriente nosso futuro articulando o que, contudo, não é para nós senão acaso. Assim, a partir dessa perspectiva, o passado não é mais "o que se sucedeu em si", algo que jaz atrás de nosso presente de maneira inexorável exercendo sobre este uma determinação fatal e irreversível, mas sim, em cada momento de nosso presente, estamos interpretando nosso passado, estamos recriando-o e o estamos reconstruindo livremente. Não se trata de algo que escape à nossa liberdade e à nossa vontade, mas sim, de algo cujo sentido para nós depende daquilo que

8 Cf. Heidegger, M. op. cit., vol. I, p. 360.

$9 \mathrm{Za} / \mathrm{ZA}$, Da visão e enigma, 2, KSA 4.199-200. 
Meca, D. S.

queiramos e decidamos no presente. E, do mesmo modo, o futuro já não é o âmbito do acaso, do totalmente imprevisível, mas sim, é o espaço onde desenvolvemos um projeto a partir de uma antecipação feita em função do nosso conhecimento do presente e de nossa reinterpretação do passado. Portanto, o futuro tampouco é algo situado à margem de nossa liberdade, de nossa capacidade de controle e da decisão de nossa vontade. Podemos, em certa medida, antecipá-lo e construí-lo livremente a partir do presente em função do sentido que quisermos lhe dar e nele projetar. Por isso, diz Nietzsche, não importa como foi o nosso passado, podemos amá-lo na medida em que sempre podemos reinterpretá-lo vivendo nele as condições que nos conduziram ao presente e a partir da vontade com a qual damos um sentido a nossa vida frente ao futuro. Por isso, esse querer o passado não é nem resignação nem fatalismo, mas sim um querer o passado ao reinterpretá-lo em íntima conexão com nosso presente e nosso futuro. Tudo isso implica conferir uma necessidade ao tempo, impor-lhe uma forma que supera a falsa idéia de sua linearidade inexorável tal como ensinaram a metafísica e a religião cristã, que separam como sendo momentos inconciliáveis e desconexos passado, presente e futuro. E isso é também o que significa assumir um destino como lei que reorganiza repetidamente nossa existência, sempre atualizando de novo as metas pelas quais nos dirigimos e, assim, tornando possível que se desdobre o impulso à superação de si (Selbstüberwindung).

Pois bem, se essa maneira de viver o tempo representa um verdadeiro apossar-se da nossa temporalidade no contexto do pós-niilismo, o que ocorre não é senão a substituição da metafísica cristã do tempo linear por uma experiência pagã do tempo como eterno retorno, na medida em que o essencial dessa nova forma de viver a temporalidade seria o retorno repetido da decisão de reunir as determinações temporais de passado, presente e futuro numa forma ou significado unificador com cuja evolução se desdobra a incessante conquista do uno mesmo. Viver o tempo como eterno retorno significa que as três dimensões do tempo se dão simultaneamente 
em cada instante da temporalidade vivida, o que torna o instante igual à eternidade. A cada instante reelaborar o presente e o passado e construir o futuro quer dizer que, ao mesmo tempo, condensamos no presente, enquanto eterno retorno passado e futuro. Como se pode agora compreender facilmente, o eterno retorno não é outra coisa senão amor fati (amor ao destino) e vontade de potência afirmativa com a qual damos um sentido à nossa existência.

Há um segundo ponto sobre o qual Nietzsche insiste quando fala do eterno retorno, a saber: a sua eficácia enquanto instrumento de discriminação entre os homens niilistas e o além-do-homem. Nietzsche esclarece essa questão dizendo que o mais importante ao homem que toma a decisão de afirmar o eterno retorno é uma mudança radical no que até agora era seu centro de gravidade. $\mathrm{Na}$ cultura européia cristã, o centro de gravidade era a idéia de Deus, fundamento último do idealismo metafísico e moral e de todas as interpretações, crenças, valores e criações que conferiam conteúdo a essa cultura. Donde se segue que, quando esse Deus "morre", ou seja, quando perde sua vigência, sua força e credibilidade por conta do efeito corrosivo do ceticismo em relação a ele, que essa cultura descobre ela mesma seu intrínseco niilismo, a reação generalizada é essa grande comoção e sentimento de desorientação que representa o niilismo passivo ${ }^{10}$. E ainda que o eterno retorno de nenhum modo esteja destinado a ocupar o lugar do Deus cristão morto à maneira de uma nova verdade religiosa absoluta, Nietzsche o pensa como o novo centro de gravidade capaz de assegurar um novo e melhor equilíbrio, capaz de dar a saúde ao indivíduo pós-niilista. Assim, é preciso que nos perguntemos: como pode uma idéia de tempo enquanto eterno retorno funcionar como novo centro de gravidade para o homem do pós-niilismo e discriminar entre niilistas e além-do-homem?

10 Nachlass/FP 1886 1887, (2) 5 [71], KSA 12.211. 
Meca, D. S.

Nietzsche faz ver que a consequência mais desastrosa para o indivíduo contemporâneo à morte de Deus é que não lhe é mais possível operar nenhuma síntese autônoma e criativa de seu projeto vital, nem sequer a síntese niilista que podia ser feita em torno do eixo da concepção linear do tempo. Com efeito, o homem niilista empenhava-se por tomar posse de sua temporalidade a partir da concepção metafísica do tempo enquanto tempo linear que se formulava fundamentalmente, como vimos, enquanto uma tradução mais ou menos racionalizada da "história cristã da salvação" (criação, pecado original, redenção e escatologia), e que tinha, pois, em Deus - como todo o resto - seu fundamento. Por isso, uma vez perdida a fé no Deus cristão, esse homem se afunda na dispersão de uma vida fragmentada em dimensões e momentos atomizados, desconexos e sem sentido, na medida em que passado, presente e futuro já não estruturam nenhum processo, já não estão encadeados por nenhum sentido unitário, tal como o da história da salvação, nem por nenhuma finalidade. De maneira que esse homem é agora vítima de um caos de determinações instáveis e que se alteram, que, de fora, agitam-no incessantemente em todas as direções, sem nenhum objetivo ou meta. A todos esses niilistas passivos, que caíram na grande depressão por conta da "morte de Deus" ao constatar $o$ absurdo extremo e sem sentido da existência, o que o pensamento do eterno retorno lhes causa é o efeito de aumentar ainda mais a sua depressão e confusão. De modo que se para alguns o eterno retorno e sua afirmação podem fazer com que adquiram um novo centro de gravidade para apossar-se de um projeto de vida mais alegre, para outros, o eterno retorno representa o contrário, a saber, o levar ao extremo sua conflitividade interna na medida em que o niilismo é conduzido à sua consumação.

Esse ponto não é difícil de entender, já que o pensamento do eterno retorno é justamente a antítese ao dualismo metafísico e moral sobre o qual os ideais e os valores do niilismo sempre se basearam. Ao se afirmar o eterno retorno do mesmo e se dizer sim à vida enquanto presente eterno, desfaz-se num só golpe a divisão 
entre mundo aparente e verdadeiro, e, portanto, a distinção entre ser e dever-ser, pois se destrói toda possibilidade de imaginar uma teleologia enquanto sentido de um plano metafísico que se desdobra através do tempo. E tudo isso torna extrema a desvalorização dos valores do indivíduo moral e lhe anula a esperança de salvação num além transcendente.

Em suma, o eterno retorno abre o horizonte para uma experiência e uma interpretação da vida que contradizem radicalmente as exigências do homem niilista que condiciona sua existência à crença num mundo supra-sensível, à luta por um dever-ser moral de valor absoluto e à esperança de salvar-se num além. Na verdade, e para sermos mais exatos, essa síntese de seu projeto vital que o homem niilista se empenhava por fazer em torno do eixo da compreensão linear do tempo era apenas uma síntese ilusória e frustrante, vítima da lógica do ressentimento própria ao niilismo. A doutrina do eterno retorno, em suma, pode servir a alguns indivíduos como novo centro de gravidade para tomarem posse de seu projeto de vida, radicalizando, assim, o niilismo, tornando extrema sua conflitividade interna e conduzindo-o à sua consumação. Pois, como é fácil notar, o pensamento do eterno retorno é a antítese total da concepção dualista do mundo sobre a qual os ideais e os valores do niilismo se basearam, na medida em que acaba com a divisão entre mundo verdadeiro e mundo aparente, destrói qualquer possibilidade de imaginar uma teleologia enquanto sentido de um plano metafísico que se desdobra através do tempo, nega a distinção entre ser e dever-ser causadora da cisão que desgarra a consciência infeliz do indivíduo moral e elimina dele qualquer esperança numa salvação num além transcendente.

Para concluir, o eterno retorno seria a resposta mais radical que se poderia opor à teleologia cristã e metafísica baseadas na temporalidade linear. No cosmo do eterno retorno não cabem nem criação nem escatologia, de maneira que se abandona por completo qualquer esperança numa redenção. No Zaratustra, o anúncio do além-do-homem vai de mãos dadas com a pregação do eterno retorno 
Meca, D. S.

porque, para aceitar a imanência total do mundo através da "morte de Deus", o homem tem de elevar-se acima de si mesmo, isto é, tem de "declinar" (Untergang) a fim de que nasça o além-do-homem, visto que só um ser “além-do-homem” (Übermensch) será capaz de afirmar a vida que retorna eternamente ${ }^{11}$. Desse modo, delineia-se também o critério básico para uma nova moral na qual liberdade e necessidade não estariam em conflito. Pois, por vir de um passado eterno, cada um de nossos atos estaria submetido à necessidade, mas, por sua vez, seria livre enquanto decisivo para uma cadeia infinita de repetições futuras. Seria preciso, então, viver cada momento de modo que se quisesse segui-lo vivendo infinitas vezes. A implicação mais importante da doutrina do eterno retorno, pois, é essa nova compreensão que representa o vínculo necessário entre o indivíduo e a totalidade da vida, ou seja, entre tempo subjetivo e tempo objetivo. Nietzsche expressa esse vínculo com a caracterização específica que dá à decisão de afirmar o eterno retorno ao designá-la como amor fati, isto é, como desejo e vontade de querer se inserir na totalidade da vida que retorna eternamente. Isto não é, como dito, o fatalismo extremo do identificar-se completamente à necessidade do mundo. A afirmação do eterno retorno não faz senão remeter o homem à sua condição de criança (no sentido que a criança tem enquanto última das três transmutações narradas no canto primeiro do Zaratustra), enquanto símbolo da vida que vive a si mesmo no presente, e que, assim existindo, reproduz o sim que a vida confere eternamente a si mesma. Por isso, o canto "Da visão e enigma" encerra-se dizendo que o instante desse ato de amor fati daquele que se diz ego fatum (ou seja, sou a vida e estou nela como num presente) não é um átomo do tempo, mas sim, simplesmente eternidade. Sentimos a eternidade da vida afirmando-se a si mesma no instante em que, com a nossa afirmação, identificamo-nos com ela ao dizer ego fatum.

11 Cf. Nachlass/FP 1881, 11 [159] e [161], KSA 9.503; Nachlass/FP 1882 1883, 4 [81] e (205) 5 [1], KSA 9.137 e 211, respectivamente.

194 I Cad. Nietzsche, São Paulo, n. 33, p. 181-196, 2013. 
Nietzsche quer abertamente ser um pós-cristão, e, para tanto, não encontra melhor caminho que o de remontar para trás, até a concepção pagã, grega e pré-individualista do tempo. Frente à religião cristã, o filósofo propõe, através da "morte de Deus", uma volta ao paganismo antigo cujos deuses agora retornariamde nada a revela como sendo sem sentido, como absurda em si mesma, sendo necess ou mais aqusado ou futuro chegam a ser momentos para nos salvar da moral niilista e de suas conseqüências. Desse modo, contra a religião enquanto consolo, ópio, desejo de morte, neurose, martírio, crucificação, obsessão pela dor, abre-se espaço à religião enquanto serenidade e afirmação da vida em sua totalidade simbolizada na figura do deus Dioniso. Não mais se identificaria a religião com a Igreja enquanto instituição de poder, mas sim, como espiritualidade e vida interior que sente o vínculo entre indivíduo e terra, e o impele a identificar-se com a totalidade do todo que existe, afirmando a vida e compreendendo-se como parte dela. É a religião que - diz Nietzsche - "alisa as almas ásperas e lhes dá a saborear um novo anseio - ficar quietas como um espelho, para que nelas se reflita o céu profundo" (JGB/BM 295, KSA 5.237).

A religião pagã nunca se compreendeu a si mesma como uma instância de moralização da sociedade, sua intenção era exaltar uma imagem da felicidade representada em seus deuses. Não consistia no tornar sagrado nenhum código moral que proclamasse as tábuas de um bem e mal transcendentes, eram as expressões sublimadas de impulsos eróticos que tendiam ao amor universal e de uma crueldade que se liberava mediante os sacrifícios e rituais litúrgicos. A religião cristã, em revanche, ao conceber-se a si mesma como moral, deixou de cumprir essa função de sublimação de afetos de vida e morte, e deixou de oferecer resposta à exigência que todo indivíduo sente por uma relação essencial com a vida do cosmo, tal como fazia a religião pagã que promovia um amor espiritualizado e um profundo reconhecimento à vida, ao ensinar aos indivíduos a viver religados à totalidade universal do universo em todos os momentos de seu vir-a-ser. 
Abstract: This article proposes an interpretation of the Eternal Return from the function that it performs in relation to the objectives of Nietzsche's thought. In other words, this article seeks its meaning in the context of the philosopher's project of transformation of European culture. It does not formulate, a Nietzschean theory about the true essence of time that would confront the metaphysical conception of linear time. In this sense, the Eternal Return is not intended to be a text directed to the understanding, but to be the expression of a challenge and task to the will. Thus, even though the doctrine of the Return has the form of a theoretical representation, the decisive element is not its validity or truth as a theory, but its value as a formula of the highest affirmation of life and as a necessary instrument of selection.

Keywords: Eternal Return - challenge - task - affirmation - selection

\section{referências bibliográficas}

1. BRUSOTTI, M. Die Leidenschaft der Erkenntnis. Philosophie und Lebenstaltung bei Nietzsche von Morgenröthe bis Also sprach Zarathustra. Berlim: de Gruyter, 1997.

2. D'IORIO, P. La linea e il circolo. Cosmologia e filosofia dell'eterno ritorno in Nietzsche. Genova: Pantograf, 1995.

3. HEIDEGGER, M. Nietzsche. Trad. J. L. Vermal. Barcelona: Destino, 2000 (vol.1).

4. NIETZSCHE, F. Sämtliche Werke. Kritische Studienausgabe in 15 Bänden. Berlim / New York: Walter de Gruyter, 1999.

5. _ Fragmentos póstumos. Sánchez Meca, D. (org.). Madrid: Tecnos, 2010. (vol III).

6. . Obras Incompletas. Trad. Rubens Rodrigues Torres Filho. $4^{\mathrm{a}}$ ed. São Paulo: Nova cultural, 1987 (Coleção "Os Pensadores").

7. SÁNCHEZ MECA, D. Nietzsche: la experiência dionisíaca del mundo. Madrid: Tecnos, 2009 (4⿳⺈冂䒑 ed.).

Artigo recebido para publicação em 20/08/2012.

Artigo aceito para publicação em 28/09/2012.

196 I Cad. Nietzsche, São Paulo, n. 33, p. 181-196, 2013. 